\title{
Digital Cadavers: Online 2D Learning Resources Enhance Student Learning in Practical Head and Neck Anatomy within Dental Programs
}

\author{
Mahmoud M. Bakr, ${ }^{1}$ Ward L. Massey, ${ }^{1}$ and Helen M. Massa ${ }^{2}$ \\ ${ }^{1}$ School of Dentistry and Oral Health, Griffith University, Gold Coast, QLD 4222, Australia \\ ${ }^{2}$ School of Medical Science, Griffith University, Gold Coast, QLD 4222, Australia \\ Correspondence should be addressed to Mahmoud M. Bakr; m.bakr@griffith.edu.au
}

Received 19 April 2016; Accepted 26 May 2016

Academic Editor: Gwo-Jen Hwang

Copyright (C) 2016 Mahmoud M. Bakr et al. This is an open access article distributed under the Creative Commons Attribution License, which permits unrestricted use, distribution, and reproduction in any medium, provided the original work is properly cited.

\begin{abstract}
Head and neck anatomy provides core concepts within preclinical dental curricula. Increased student numbers, reduced curricula time, and restricted access to laboratory-based human resources have increased technology enhanced learning approaches to support student learning. Potential advantages include cost-effectiveness, off-campus access, and self-directed review or mastery opportunities for students. This study investigated successful student learning within a first-year head and neck anatomy course at the School of Dentistry and Oral Health, Griffith University, Australia, taught by the same teaching team, between 2010 and 2015. Student learning success was compared, for cohorts before and after implementation of a supplementary, purpose-designed online digital library and quiz bank. Success of these online resources was confirmed using overall students' performance within the course assessment tasks and Student Evaluation of Course surveys and online access data. Engagement with these supplementary 2D online resources, targeted at improving laboratory study, was positively evaluated by students (mean 85\%) and significantly increased their laboratory grades (mean difference $6 \%, P<0.027$ ), despite being assessed using cadaveric resources. Written assessments in final exams were not significantly improved. Expanded use of supplementary online resources is planned to support student learning and success in head and neck anatomy, given the success of this intervention.
\end{abstract}

\section{Introduction}

Increased numbers of students enrolling in university degree programs and a trend towards provision of newer, more flexible opportunities for students to supplement their learning include online resources and distance education or teaching [1]. A number of studies have investigated the value and effectiveness of online anatomy courses versus traditional on-campus face-to-face methods of delivery, with the consensus by students within all previous reports being that both online and on-campus methods were equally effective $[1,2]$. Combining online components with limited access laboratory resources can be a valuable addition to the oncampus face-to-face traditional teaching. This constitutes a "hybrid" or "blended" type of course [3]. This combination resulted in either a superior outcome in learning $[4,5]$ or no change in learning outcomes when compared to traditional face-to-face methods [6-8]. Advantages of online resources may include cost-effectiveness in teaching resources access and provision, reduced academic staffing costs (after design and development of resources), and improved flexibility and availability of learning opportunities for students off campus at any time [9]. A major disadvantage of the use of online resources to supplement anatomy learning is the potential risk of concurrent reduction in laboratory classes which results in reduced opportunity for collegiate interactions between students, which facilitate communication and interpersonal negotiation and management skills and often may result in reduction in students' or learners' contact with their teacher $[10,11]$. With increased numbers of students from the millennial generation undertaking university programs of study, this majority of students are better skilled to access and effectively utilise new technology to support their learning [12]. The changing student cohort and their familiarity and 
engagement with technology are a major contributing factor to universities actively seeking to drive the paradigm shift towards embracing new advances in technology as tools in education $[13,14]$.

Anatomy learning and teaching have evolved through different phases starting with surface anatomy, cadaveric dissection, prosected cadaveric specimens, plastic models, use of imaging modalities including ultrasonic, radiological, and computer tomography and magnetic resonance imaging, body painting for study of surface anatomy, elearning resources using different multimedia sources, and recently sensory input using haptic simulators [15]. Social media is also reported to be a useful tool in education $[16$, 17]. The increasing trend for non-laboratory-based learning experiences that support more self-directed approaches to student learning may also result from increased challenges influencing the teaching of introductory science courses. These challenges include increasing numbers of student enrolments, progressive reduction in allocated curricular and teaching time, expense or challenges in accessing the discipline-specific resources, including availability of donated bodies for dissection programs, alteration of curriculum that condenses curricula while expanding the focus on addressing relevant clinical applications, and accreditation bodies' requirements in other discipline areas such as professionalism and communication skills [15, 18-22].

In dental education, head and neck anatomy is a critical and integral keystone within preclinical years program curricula that forms the foundation of and scaffolds to development of more specialised clinical course knowledge such as orthodontics and oral surgery. Every competent dental practitioner requires comprehensive understanding of head and neck anatomy to optimise safe practice and is central to quality assurance for performance of routine dental practice including but not limited to administration of local anaesthetics and tooth repair or extraction. Similarly, in medical education, new medical graduates and recently qualified doctors are reported to feel less confident in everyday practice and even unprepared as a result of their perceived lack in anatomical knowledge [23, 24]. Furthermore, career development and professional choices are reported to be affected by a practitioner's level of anatomical knowledge, especially where the knowledge is considered inadequate [25-27].

In this study, we report on the use of $2 \mathrm{D}$ online resources in teaching head and neck anatomy to support student learning by undergraduate first-year dental science and dental technology students. To establish the effect on successful student learning, the developed resources were used as a supplementary resource in a hybrid mode offering of an established course that used traditional lecture and practical laboratory sessions.

\section{Aim and Objectives}

This study aimed to investigate the impact of utilisation of $2 \mathrm{D}$ online resources, over a period of three years, in the delivery of the practical course component of a first-year head and neck anatomy course delivered as a core course for first-year dental science and dental technology students enrolled in the School of Dentistry and Oral Health, Griffith University, Gold Coast, Australia.

The objectives were as follows:

(1) To assess students' perception of the value of $2 \mathrm{D}$ online resources in supporting their practical course learning, through course evaluation surveys as a tool for feedback collection.

(2) To assess the effectiveness of the $2 \mathrm{D}$ online resources in supporting students to acquire curricula knowledge through monitoring and comparison of students' overall performances in written and practical assessments throughout a period of six years, during which, the first three years (2010, 2011, and 2012) delivered the practical component of the course using traditional methods including dry specimens (skulls, vertebrae), wet specimen (cadavers), and plastic models, while in the subsequent three years (2013, 2014, and 2015) the same practical component of the same course was delivered by the same lecturer and convenor, supplemented by the use of $2 \mathrm{D}$ online learning resources, in addition to the traditional teaching methods that were used previously in the same course.

\section{Study Design}

The head and neck anatomy course used in the present study was first developed in its current form and curricula content in 2010 to be delivered to students enrolled in the Bachelor of Oral Health (Dental Science) and the Bachelor of Oral Health (Dental Technology). The Bachelor of Oral Health (Dental Science) is a five-year program and the Bachelor of Oral Health (Dental Technology) is a three-year program. However, students from both cohorts study the same basic science content and subjects including this head and neck anatomy course. The course has been delivered by the same lecturer for six years (2010-2015) using traditional methods, with the practical laboratory sessions including dry specimens (skulls, vertebrae), wet specimen (cadavers), and plastic models. The course runs over the period of 13 weeks and includes the delivery of 3 hours of didactic lectures per week as well as a single 2-hour practical laboratory session per week (refer to Table 1 for the course map). A final practical exam that is weighed $20 \%$ of the overall mark for the course and an end-of-semester written exam that is weighed $80 \%$ of the overall mark of the course are the means of assessment in this course. In addition to the above, two formative assessments are offered in the course in the midsemester period and towards the end of semester.

In 2013, in an effort to provide a more flexible delivery of support for student learning, the laboratory sessions were augmented with the design and construction of a series of $2 \mathrm{D}$ videos, delivered as online resources. Overall, the lectures and the opportunity for students to develop and perfect practical skill development within the practical classes was unchanged but an online digital library was created, which included photos of all dry and wet specimens used in practical 
TABLE 1: A course map for the head and neck anatomy course, identifying curricular knowledge areas, learning environment modalities, and integration of lectures, practical laboratory sessions, and assessment items. Later offerings of the course included access to the online resources/digital library through the Griffith University Blackboard-based learning management system.

\begin{tabular}{|c|c|c|}
\hline Topic & Practical labs, online videos/digital library & Assessment \\
\hline $\begin{array}{l}\text { Embryology of head and neck region } \\
\text { Design of the head and neck }\end{array}$ & \multirow{2}{*}{ Osteology, skull (dry specimens) } & Online and in-class quiz \\
\hline Osteology of the skull and vertebrae & & Online and in-class quiz \\
\hline $\begin{array}{l}\text { Temporomandibular joint (TMJ) } \\
\text { mandible at different ages }\end{array}$ & Osteology, mandible (dry specimens) & Online and in-class quiz \\
\hline Muscles of mastication & Muscles of the head and neck (wet specimens) & Online and in-class quiz \\
\hline Muscles of facial expression & \multirow[b]{2}{*}{ Muscles of the head and neck (wet specimens) } & Formative assessment \\
\hline Triangles and muscles of the neck & & Online and in-class quiz \\
\hline $\begin{array}{l}\text { Introduction to nervous system: somatic and visceral nervous } \\
\text { system }\end{array}$ & \multirow{2}{*}{$\begin{array}{l}\text { Introduction to nerve supply of teeth and } \\
\text { demonstration of local anaesthetic technique } \\
\text { (wet specimen) }\end{array}$} & Online and in-class quiz \\
\hline $\begin{array}{l}\text { Trigeminal nerve: ophthalmic (V1), maxillary (V2), and } \\
\text { mandibular (V3) divisions }\end{array}$ & & Online and in-class quiz \\
\hline Cranial nerves VII, IX, X, and XII & $\begin{array}{l}\text { Cranial nerves (wet specimens and plastic } \\
\text { models) }\end{array}$ & Online and in-class quiz \\
\hline Arterial blood supply in the head and neck & $\begin{array}{l}\text { Arterial blood supply (wet specimens and } \\
\text { plastic models) }\end{array}$ & Online and in-class quiz \\
\hline Venous drainage in the head and neck & $\begin{array}{l}\text { Venous drainage (wet specimens and plastic } \\
\text { models) }\end{array}$ & Formative assessment \\
\hline Lymphatic circulation in the head and neck & $\begin{array}{l}\text { Lymphatic circulation (wet specimens and } \\
\text { plastic models) }\end{array}$ & Revision \\
\hline Tissue spaces and spread of infecti & $\begin{array}{l}\text { Cross section of the neck (wet specimens and } \\
\text { plastic models) }\end{array}$ & Final practical exam \\
\hline
\end{tabular}

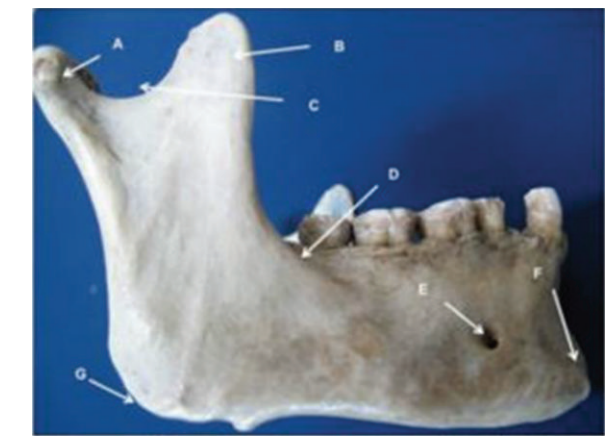

The coronoid process is represented on the image by the label.. $\mathrm{A} \bigcirc \mathrm{B} \bigcirc \mathrm{C} \bigcirc \mathrm{D} \bigcirc \mathrm{E} \bigcirc \mathrm{F} \bigcirc \mathrm{G}$

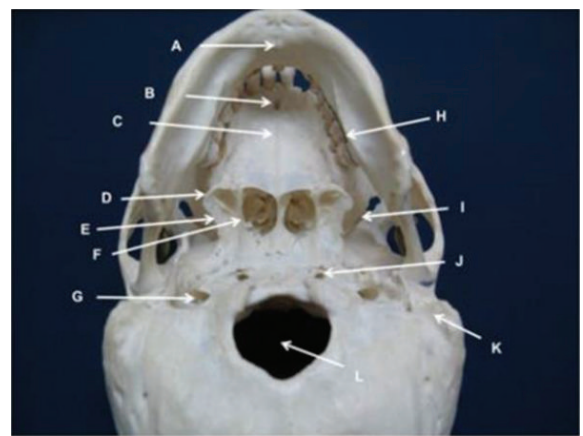

Which letter represents the Jugular Foramen $\circ \mathrm{A} \odot \mathrm{B} \odot \mathrm{C} \odot \mathrm{D} \odot \mathrm{E} \odot \mathrm{F} \odot \mathrm{G} \odot \mathrm{H} \odot \mathrm{I} \odot \mathrm{J} \odot \mathrm{K} \odot \mathrm{L}$

FIgURE 1: Two examples of the online digital library and online quiz images developed for the course reported in this study.

laboratory sessions. These resources were developed as a series of self-directed online quizzes that addressed all core conceptual knowledge that was previously only taught within the practical laboratory sessions. These quizzes were created using a similar style to that utilised in written and practical assessments (Figures 1, 2, and 3). Students were permitted to attempt the online quizzes as many times as they want and once they achieved a score of $80 \%$ or more in a quiz, their score unlocked a "trophy" which was the master image, a fully labelled image that identified and summarized the relevance of all structures related to that region the specific quiz was assessing. Completion of all the quizzes successfully provided students with a comprehensive online digital library of images for self-directed review during their studies.

To facilitate student evaluation of the perceived value of the $2 \mathrm{D}$ online resources used in this study, three questions were added to the standard Student Evaluation of Course (SEC). Each student has the opportunity to complete the SEC anonymously at the end of every semester through a centrally administrated Griffith University process. The standard SEC questions relate to organization, engagement, effectiveness, and overall student satisfaction of the course. Additional questions assessed the quality of the online resources developed, the student's perception of the value of 


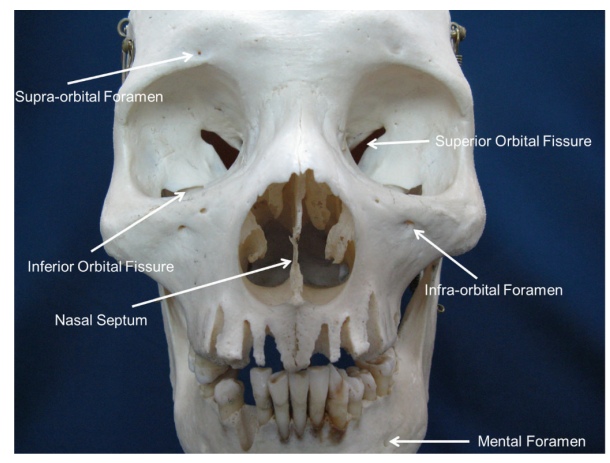

FIGURE 2: An example of a trophy image, unlocked after successful completion of one of the online quizzes (dry specimen).

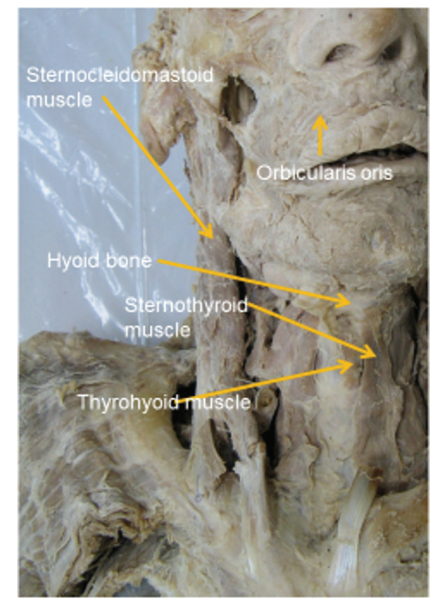

Figure 3: An example of one of the trophy images unlocked after successful completion of one of the online quizzes (wet specimen).

the online resources in helping them succeed in the course, and the efficiency of using a blended form of face-to-face and online resources in delivering the course. All questions used a 5-point Likert scale, where 1 represents "strongly disagree" and 5 represents "strongly agree." Students could also provide their reflections on their experience with the 2D online resources and the course overall in an open ended comment section of the evaluation. Comparative statistical analysis of the overall performance of students, in written and practical assessments over the period of six years, was performed, in order to determine whether the $2 \mathrm{D}$ online resources introduced in this study were valued by students to support their learning as well as being effective in promoting student achievement of learning objectives within the course.

\section{Results}

4.1. Sample Size. The number and average age of students enrolled in the head and neck anatomy course as well as the Student Course Evaluation response rates remained consistent over the six years' period of the study (see Table 2).
TABLE 2: Showing student enrolment, average age, and SEC response rates in the head and neck anatomy course for the period of 20102015 , the duration of the study.

\begin{tabular}{lcccccc}
\hline & \multicolumn{6}{c}{ Year } \\
& 2010 & 2011 & 2012 & 2013 & 2014 & 2015 \\
\hline $\begin{array}{l}\text { Enrolment } \\
\begin{array}{l}\text { Average age } \\
\text { (years) }\end{array}\end{array}$ & 124 & 114 & 130 & 127 & 133 & 117 \\
$\begin{array}{l}\text { SEC response } \\
\text { rate }\end{array}$ & 46.3 & 25.6 & 24.2 & 25.1 & 23.7 & 23.4 \\
\hline
\end{tabular}

\subsection{Student Evaluation of Course (SEC) Data}

4.2.1. Five-Point Likert Scale Standard SEC Questions. The use of the online resources clearly had a very positive result on the students' ratings of the course in the standard SEC questions. The mean score for all questions increased significantly $(P \leq 0.05)$ with introduction of the supplementary online resources. The responses to the standard SEC questions are summarized in Table 3.

Three questions, additional to the standard SEC, were specifically directed at encouraging student evaluation of their perception of the value of the online resources in supporting their learning and its success, within the course (see Table 4). Overall, the online resources were valued as assisting student learning by the students answering the SEC, with only $3.4 \%-5.25 \%$ of respondents identifying the fact that they disagreed or strongly disagreed with the statement. Interestingly, between $10 \%$ and $17 \%$ of students were neutral in their response to the value of these resources.

4.2.2. Open Ended Comments. Students commented positively on the value of the online resources that were made available in the head and neck anatomy course. Examples of the comments that the students quoted are shown below:

\footnotetext{
"The subject was extremely challenging but was presented in a way that was engaging and interesting. It was generally well organised and there were a plethora of resources for students to use to enhance their knowledge. For example, the Anatomy Library resource was very well set out, and was useful to prepare for exams and practice".

"I really enjoyed the addition of online study sources to assist with head and neck anatomy - this included the Digital Head and Neck library. The reason for this is we are limited in our chances to look at wet specimens once out of the lab; however, the online images help students visualise the anatomy and to revise what was taught hands on in the practical labs".

"There were a lot of resources online such as head and neck library as well as help from the lecturers and tutors. The head and neck library along with practice lab exams were ideal preparation for the lab exam. The labs were extremely interesting and I enjoyed examining cadavers for nerves and blood vessels for example".
} 
TABLE 3: Showing a summary of the SEC standard questions' results obtained over the period of the study before and after the introduction of the $2 \mathrm{D}$ online resources $(P<0.05$ was used to establish significance).

\begin{tabular}{lccc}
\hline Standard SEC question & $\begin{array}{c}\text { Average SEC before } \\
\text { online resources }\end{array}$ & $\begin{array}{c}\text { Average SEC after } \\
\text { online resources }\end{array}$ & $\begin{array}{c}P \text { value (single } \\
t \text {-test) }\end{array}$ \\
\hline (1) This course was well-organised. & 3.35 & 3.76 & $P=0.05$ \\
(2) This course engaged me in learning. & 3.7 & 4.03 & $P=0.026$ \\
$\begin{array}{l}\text { (3) The teaching (lecturers, tutors, online etc.) in this } \\
\text { course was effective in helping me to learn. }\end{array}$ & 3.8 & 4.06 & $P=0.039$ \\
(4) Overall, I am satisfied with the quality of this course. & 3.3 & 3.8 & $P=0.05$ \\
\hline
\end{tabular}

TABLE 4: Showing a summary of the results of the additional SEC questions related to the online resources developed in the head and neck anatomy course. SA: strongly agree, A: agree, N: neutral, D: disagree, and SD: strongly disagree.

\begin{tabular}{|c|c|c|c|c|c|}
\hline Question & Score & $\begin{array}{l}\%+v e \\
\%-v e\end{array}$ & Median & Std deviation & Mean \\
\hline $\begin{array}{l}\text { The online learning activities helped me to succeed in } \\
\text { this course. }\end{array}$ & $\begin{array}{l}\mathrm{SA}=51 \% \\
\mathrm{~A}=34.45 \% \\
\mathrm{~N}=10.05 \% \\
\mathrm{D}=3.8 \% \\
\mathrm{SD}=0.7 \%\end{array}$ & $\begin{array}{l}+85.4 \% \\
-3.8 \%\end{array}$ & 4.75 & 0.85 & 4.3 \\
\hline $\begin{array}{l}\text { The blend of face to face and online learning and } \\
\text { teaching was effective for my learning in this course. }\end{array}$ & $\begin{array}{l}\mathrm{SA}=30.45 \% \\
\mathrm{~A}=47.2 \% \\
\mathrm{~N}=17.15 \% \\
\mathrm{D}=4.75 \% \\
\mathrm{SD}=0.5 \%\end{array}$ & $\begin{array}{l}+77.6 \% \\
-4.8 \%\end{array}$ & 4 & 0.845 & 4.05 \\
\hline $\begin{array}{l}\text { The use of online technologies provided me with access } \\
\text { to effective learning materials and resources. }\end{array}$ & $\begin{array}{l}\mathrm{SA}=47.4 \% \\
\mathrm{~A}=38.3 \% \\
\mathrm{~N}=10.9 \% \\
\mathrm{D}=2.05 \% \\
\mathrm{SD}=1.35 \%\end{array}$ & $\begin{array}{l}+85.7 \% \\
-3.4 \%\end{array}$ & 4.5 & 0.75 & 4.25 \\
\hline
\end{tabular}

"Overall, I felt the depth and breadth of material covered was very good and I liked that we were given extra digital resources to assist in our studies. For example the digital head and neck anatomy resource allowed me to better prepare for our lab exams as there were questions that incorporated dry and wet specimens".

"The digital head and neck library was very useful as we could view the wet specimens and bones and test ourselves on it in our own time rather than just in the labs. The online quizzes \& images allowed us to understand \& solidify concepts learnt in class".

"The Digital Anatomy Library was a great support tool for learning the required anatomical structures".

"Receiving the Online Digital Anatomy Library was extremely thoughtful and helpful. I feel that it assisted a lot in learning, especially when wet specimen examination is extremely ambiguous and difficult".

"New Online Digital Learning System helped me to memorize the important features on the bone and cadaver (especially the nerves and blood vessels). It also provide random quiz for us to test our own knowledge and study results which is a really helpful system to study the course content".

\begin{abstract}
"The digital anatomy library encouraged me to study and test my knowledge, it allowed me to self-learn at home, by viewing all the questions I got wrong so that I know what to focus my study on".

"Digital Anatomy Library was beyond exceptional, it helped me tremendously in my study".
\end{abstract}

4.3. Students' Usage and Access to Online Resources. All students attempted the online quizzes at least once. More than one-third of the students attempted the online quizzes more than once. The average number of attempts per student was 3.2 and the maximum number of attempts for a single student was seven attempts. The results obtained after analysis of students' usage of the digital online head and neck anatomy library are summarized in Figure 4.

4.4. Students' Performance in Online Quizzes. The percentage of students that unlocked all trophy images and completed all online quizzes successfully was $97 \%$. This was in consistency with the students' overall results in the formative assessments and the final practical exam, where students achieved an overall pass rate of $98.6 \%$.

4.5. Overall Students' Performance in the Head and Neck Anatomy Course. There was a significant improvement in the overall students' performance in the final practical exam 


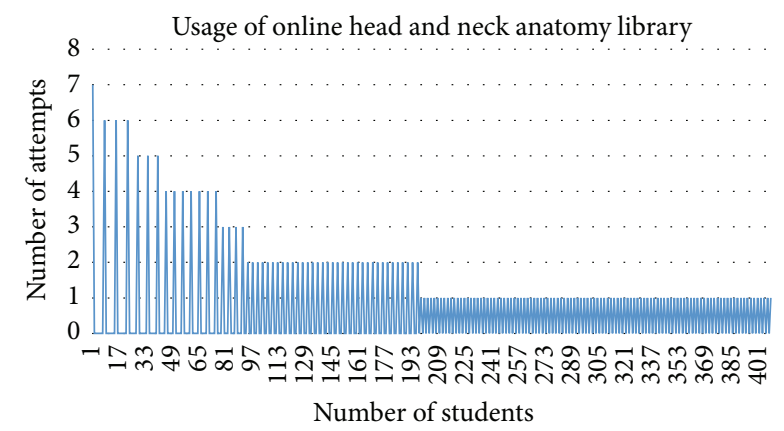

FIgURE 4: A summary of the students' usage of the online head and neck anatomy library investigated in this study. The number of students is shown on the $x$-axis and the number of attempts is shown on the $y$-axis.

after implementing the online resources that augmented the practical components of the course. Interestingly, this positive outcome was not observed in student performance in the end-of-semester written exam. Successful learning and enhanced assessment performance observed after the introduction of the online resources contributed to increased numbers of students being awarded a grade of "High Distinction" (HD) ( $\uparrow 9.36 \%)$ and reduced numbers of "fail" (F) grade being awarded ( $\downarrow 4 \%)$. The overall results of students' performance before and after applying the online resources are summarized in Tables 5 and 6.

\section{Discussion}

Anatomy teaching, illustration, and demonstrations have progressively evolved over a long period of time [28] to support student learning and resource usage. Computer systems, online technologies, simulation, photography, and $3 \mathrm{D}$ imaging are increasingly used in anatomical education [29-31] and assist in the structural identification and language development necessary for successful study in this discipline. Multimodal approaches to supporting student learning maximise the opportunity for successful learning of anatomy and no single modality of anatomy teaching has been identified as the ideal approach. In this study, 2D images, using an online self-directed quiz template developed via the Blackboard Management System, were used in combination with a successful albeit traditional designed course offering in head and neck anatomy. The traditional mode included practical laboratory sessions, didactic lectures, and practical and written examinations in a head and neck anatomy course for dentistry students. This methodological approach was adopted in a previous study in Canada where an online course consisting of online lectures, online demonstrations using Netter's 3D Interactive Anatomy, and online supplementary material that was made available through the course website was offered parallel to a traditional face-to-face course. Results from the abovementioned study showed that previous academic merits of students not the format of course delivery dictated their performance and achievement in anatomy courses [32]. It should be noted that results from both studies could be compared despite the difference in the technology
TABLE 5: Showing a summary of the overall students' performance in all assessment tasks before and after using the online resources $(P<0.05$ was used to establish significance).

\begin{tabular}{lccc}
\hline Assessment & $\begin{array}{c}\text { Average student } \\
\text { performance } \\
\text { (\%) before } \\
\text { online resources }\end{array}$ & $\begin{array}{c}\text { Average student } \\
\text { performance } \\
(\%) \text { after online } \\
\text { resources }\end{array}$ & $\begin{array}{c}P \text { value } \\
\text { (single } t \text {-test) }\end{array}$ \\
\hline $\begin{array}{l}\text { Final practical } \\
\text { exam }\end{array}$ & $85.4 \%$ & $91.06 \%$ & $P=0.027$ \\
$\begin{array}{l}\text { End-of-semester } \\
\text { written exam }\end{array}$ & $73.5 \%$ & $72.5 \%$ & $\begin{array}{c}P \text { value } \\
\text { statistically } \\
\text { insignificant }\end{array}$ \\
\hline
\end{tabular}

used in each study and showed that simple tools were effective for all students. The complex tools disadvantaged those students with low spatial ability in anatomy education [33].

In this study, students offered the combination of both face-to-face learning environments and self-directed online resources, resulting in a better overall performance for students in the course. It is noted that the class consisted of students with a wide variety of academic capital or achievement through the university entrance requirements for their program (dental technology versus dental science), which are based on the student's previous academic achievement. A range of student ages, from mid-late teenage high school leavers and non-school leavers, are represented within the samples and did not result in differences between the cohorts. Thus, new technology and the recent trends and shift towards online modules and simulation clearly can supplement traditional face-to-face methods for a range of students. Inclusion and participation in the on-campus laboratory learning experiences, including peer-to-peer and student-tutor interaction as well as textbooks, remain valuable contributors to student learning and their educational process [34-37].

The successful integration of online resources and their support in student learning and overall successful study within a course and its cohorts has been previously reported [38]. The results from the present study clearly demonstrated a significant improvement in students' overall performance only in the practical assessment tasks which is weighted at $20 \%$ of the overall grade of the course. Furthermore, access and use of online resources had a positive effect on students' performance at the top quartile (increase in the number of high achieving students awarded a High Distinction), as well as a significant decrease in the number of students at the bottom quartile (students awarded with a fail). This result highlights that the weighting of assessments in which student performance was enhanced helped improve the overall results of students and the achievement of the course learning outcomes. This was demonstrated through the significant increase in the number of students achieving a High Distinction (HD) grade, as well as a significant decrease in the number of students awarded a fail $(F)$ grade. In addition, formative assessments provided throughout the whole semester in the practical laboratory sessions contributed to the improvement in the overall performance in practical exams noted in our study. Formative assessment is recognised 
TABLE 6: Showing a summary of the percentages of students awarded different grades over the period of the study before and after using the online resources in the head and neck anatomy course $(P<0.05$ was used to establish significance).

\begin{tabular}{lccc}
\hline Grade & $\begin{array}{c}\text { Average percentage of } \\
\text { grades awarded before } \\
\text { online resources }\end{array}$ & $\begin{array}{c}\text { Average percentage of } \\
\text { grades awarded after online } \\
\text { resources }\end{array}$ & $P$ value (single $t$-test) \\
\hline High Distinction (HD) $>85 \%$ & $16.2 \%$ & $25.56 \%$ & $P=0.04$ \\
Distinction (D) $75 \%-84.5 \%$ & $39.2 \%$ & $28.5 \%$ & $P=0.02$ \\
Credit (C) $65 \%-74.5 \%$ & $14.6 \%$ & $21.1 \%$ & $P=0.045$ \\
Pass (P) $50 \%-64.5 \%$ & $12.3 \%$ & $12.96 \%$ & $P$ value statistically \\
insignificant & $P=0.048$ \\
Fail (F) $<50 \%$ & $5.4 \%$ & $1.4 \%$ & $P$ \\
\hline
\end{tabular}

as an important factor that contributes to a continuous loop of learning and feedback for each student, as well as promoting active learning for longer periods over the semester, rather than a single intense and focused period before summative assessments [39-43].

Student performance in end-of-semester written assessment tasks remained unchanged after using of the online resources, since these resources were designed to augment the practical laboratory content, rather than explanatory lecture content. This finding is consistent with a previous report that a radiological anatomy e-learning module was investigated and resulted in better knowledge of topics related to the radiological anatomy e-learning module when compared to other topics that were not relevant to the e-learning resource [44]. This result suggests that the effect of using online resources increases familiarity with curricula content and knowledge within the limits of the context in which the online resources are provided and that additional design focus may be needed to widen the applicability of the learning outcomes to more general conceptual understanding. Future innovations for this course could utilise and explore this result by designing and testing additional online resources that focus on scaffolding the lecture and laboratory content. Ultimately, these resources may be utilised to investigate the effectiveness of a flipped classroom approach for supporting student learning in this course, due to their learning outcomes including significant visual recognition, conceptual understanding of the structures, and their application in the practical skill development for dental students.

Replacement of in-class lecture experiences with learning human embryology through provision of a series of online videos of embryology was reported to not improve student performance compared to traditional course offerings [45]. The current results and this report may indicate that online resources may provide more benefit in the demonstration and acquisition of practical skills rather than teaching theoretical concepts and basic knowledge. More innovative methods are needed to improve learning outcomes and motivate students' engagement with learning of complex curricula and have extended to the use of limerick writing [46] and anatomical cartoons [47] to enhance student learning of human anatomy.

A principle advantage of online quizzes is that students are provided with a safe (risk-free) environment for establishing and risking their anatomical knowledge, with feedback, at their own pace, prior to undertaking summative assessments.
Reflections of teaching staff within the practical classes of this course identified the notion that a significant number of students had identified their areas of weakness with particular aspects of head and neck anatomy, through the repeated use of the resources, and then approached teaching staff during labs with specific requests for assistance to address these knowledge gaps. Prior to implementation of the online resources, students were more likely to request "what do I need to know about..." when requesting help in the labs. Furthermore, it was recognised that, during different assessment tasks, the mistakes made by the students were more frequently better aligned and more related and closer to the correct answer than those prior to availability of the resources when compared to relying on traditional teaching methods. It is sensible that practice and the amount of time spent in repetition of a certain task correlate positively with better performance. For example, in the field of problem based medical education, there was a clear association between the number of practice hours on a high fidelity medical simulator and the achievement of a set of standardized learning outcomes [48]. A future project aims to investigate this result by examination of the pattern of student access and use of resources to determine the extent to which multiple attempts using the online resources could contribute to explaining this observation.

Clearly, the use of another form of formative assessments provides increased opportunity for validation and correction of existing knowledge and its application. Quality assurance of knowledge through the use of formative assessments is recognised as a very powerful tool in identifying students at risk during their study of clinical anatomy [49]. In the present study, student performance in the online quizzes was consistent with their performance in formative assessments throughout the semester and the final practical exam, despite these assessments being paper based. The mode of assessment administration has been previously reported to not influence mean grades in anatomy practical examinations conducted either online or using the traditional format [50].

Our results showed that students' quantitative responses in SECs were significantly higher after using the online resources. Online resources were valuable in increasing students' satisfaction about the quality, organization of the course, effectiveness of teaching staff, and resources as well as engagement. Students' comments in the SECs appreciated the immediate feedback provided through the online resources. 
This is typical of a generation who expects no delays and requests immediate responses to all their needs to the extent that they were described to be operating at a "twitch speed" [51]. In addition, students emphasised that all images in the online resources created in this study were actually taken from similar or the same specimens they may use during their practical laboratory sessions. This element of familiarity is highly important in giving students a sense of security and confidence while revising before assessment tasks. These online resources serve as an archive, since prosected specimens and cadavers donated for use in the program may have designated periods of usage, since some bodies are only donated for a fixed term rather than continuing period, after which they are cremated for interment. The online digital library allows indefinite viewing and usage by students, at times of their convenience and frequency, whose value adds to the time taken to prepare and present these unique specimens.

The online resources provide the opportunity for refreshment of core anatomical knowledge and understanding, in a flexible and private manner. Indeed, long term retention of basic science knowledge, such as anatomy, taught in preclinical years has always been problematic, as reported by a number of studies that demonstrated that basic information acquired in earlier preclinical stages of health programs are often lost during clinical years, even before graduation [5256]. The value of the online resources created during the period of this study not only is limited to the increased students' satisfaction and achievement of learning outcomes in the head and neck anatomy course in the first instance but also may contribute to ongoing professional education, where flexibly offered self-directed formative assessments, similar to the resources developed for this study, may be used for revision and refreshment in their senior years, during postgraduate studies, professional training courses, and future careers.

\section{Future Directions}

Social media is another learning and teaching modality that is being used to support successful learning in higher education, as exemplified by YouTube to YouNversity, which is an online platform facilitating communication of students with their peers and networking with people sharing the same interests including industry partners and stakeholders [57]. YouTube has also been described as a powerful tool in anatomy instruction and YouTube channels have been used to support independent learning and integration in a Problem Based Learning (PBL) curriculum [58]. In another report by the same authors, Facebook was found to be useful in providing a venue to enhance classroom teaching without intruding into students' social life [59]. Unfortunately, given the potentially confronting images and the obligations for the use of images obtained from the Griffith University School of Anatomy Body Bequest program donors, social media or open access to the resources could not be investigated for this study. Currently, all online resources used in this study were initially only made available to first-year dentistry students at the School of Dentistry and Oral Health, Griffith
University, Australia, who are enrolled in the head and neck anatomy course and could only be viewed exclusively through individual student log into the course website via Blackboard platform. Following the successful application within the first-year course, the online resources were then made available for access by senior students as well for refreshment before clinical courses such as oral surgery and before Objective Structured Clinical Examinations (OSCEs). In future, we are planning to extend the usage of these valuable resources across other faculties within the health group. This supports the new coursework and program designs that shifted from a discipline-specific approach in teaching basic introductory sciences to a more amalgamated interprofessional approach [60-62].

Interestingly, the current head and neck anatomy course used in this study does not provide students with the opportunity to perform explorative dissection, to investigate the regional anatomy in unfamiliar specimens, and to develop the manipulative skills to perform more complex surgery within the region. Access to resources, student numbers, and curricular condensation typically precludes the opportunity for first-year students to perform dissection in most programs. Importantly, students studying courses that include dissection and prosection exercises are reported to have performed better in the United States Medical Licensing Examination (USMLE) than their peers studying in courses where only dissection is offered [63]. Future development of online technologies to support student learning may include the use of haptic simulation in dissection and prosection, particularly if real time experience in these fields could not be provided.

\section{Conclusion}

Development and use of $2 \mathrm{D}$ online resources to support student learning of head and neck anatomy in a core course undertaken by first-year dentistry students in the School of Dentistry and Oral Health, Griffith University, Australia, were very positive. Students recognised and appreciated the advantages of this modality for supporting their learning but identified the notion that a blended learning approach, using both traditional and online learning environments, was optimal. The overall performance of the class in practical assessments improved, while the overall academic achievement of students in written assessments remained unchanged. The results obtained are supportive of expanding the use of more online resources such as $3 \mathrm{D}$ images, discussion forums [64], and online platforms for anatomical terminology [65] in conjunction with traditional teaching methods using a hybrid or blended learning environment. In future, use of 3D imaging, virtual reality, and haptic simulations may further expand student engagement and success with anatomical learning and practical skill development, well beyond the traditional laboratory class or clinical learning environments.

\section{Competing Interests}

The authors declare that there are no competing interests regarding the publication of this paper. 


\section{References}

[1] M. L. Barbeau, M. Johnson, C. Gibson, and K. A. Rogers, “The development and assessment of an online microscopic anatomy laboratory course," Anatomical Sciences Education, vol. 6, no. 4, pp. 246-256, 2013.

[2] R. M. Bernard, P. C. Abrami, Y. Lou et al., "How does distance education compare with classroom instruction? A meta-analysis of the empirical literature," Review of Educational Research, vol. 74, no. 3, pp. 379-439, 2004.

[3] J. G. Ruiz, M. J. Mintzer, and R. M. Leipzig, "The impact of elearning in medical education," Academic Medicine, vol. 81, no. 3, pp. 207-212, 2006.

[4] H. Rosenberg, J. Kermalli, E. Freeman, H. Tenenbaum, D. Locker, and H. Cohen, "Effectiveness of an electronic histology tutorial for first-year dental students and improvement in 'normalized' test scores,' Journal of Dental Education, vol. 70, no. 12, pp. 1339-1345, 2006.

[5] J. A. McNulty, B. Sonntag, and J. M. Sinacore, "Evaluation of computer-aided instruction in a gross anatomy course: a sixyear study," Anatomical Sciences Education, vol. 2, no. 1, pp. 2-8, 2009.

[6] B. S. Bryner, D. Saddawi-Konefka, and T. R. Gest, "The impact of interactive, computerized educational modules on preclinical medical education," Anatomical Sciences Education, vol. 1, no. 6, pp. 247-251, 2008.

[7] A. M. Dantas and R. E. Kemm, "A blended approach to active learning in a physiology laboratory-based subject facilitated by an e-learning component," American Journal of PhysiologyAdvances in Physiology Education, vol. 32, no. 1, pp. 65-75, 2008.

[8] A. H. Mahnken, M. Baumann, M. Meister, V. Schmitt, and M. R. Fischer, "Blended learning in radiology: is self-determined learning really more effective?" European Journal of Radiology, vol. 78, no. 3, pp. 384-387, 2011.

[9] Y. H. Sung, I. G. Kwon, and E. Ryu, "Blended learning on medication administration for new nurses: integration of elearning and face-to-face instruction in the classroom," Nurse Education Today, vol. 28, no. 8, pp. 943-952, 2008.

[10] T. A. Stuckey-Mickell and B. D. Stuckey-Danner, "Virtual labs in the online biology course: student perceptions of effectiveness and usability," MERLOT Journal of Online Learning and Teaching, vol. 3, no. 2, pp. 105-111, 2007.

[11] L. S. Hale, E. A. Mirakian, and D. B. Day, "Online vs. classroom instruction: student satisfaction and learning outcomes in an undergraduate allied health pharmacology course," Journal of Allied Health, vol. 38, no. 2, pp. e36-e42, 2009.

[12] W. Strauss and N. Howe, Generations: The History of America's Future, 1584 to 2069, William Morrow and Company, New York, NY, USA, 1st edition, 1991.

[13] K. Mangold, "Educating a new generation: teaching baby boomer faculty about millennial students," Nurse Educator, vol. 32, no. 1, pp. 21-23, 2007.

[14] C. Dilullo, P. Mcgee, and R. M. Kriebel, "Demystifying the Millennial student: a reassessment in measures of character and engagement in professional education," Anatomical Sciences Education, vol. 4, no. 4, pp. 214-226, 2011.

[15] K. Sugand, P. Abrahams, and A. Khurana, "The anatomy of anatomy: a review for its modernization," Anatomical Sciences Education, vol. 3, no. 2, pp. 83-93, 2010.

[16] M. Hall, L.-A. Hanna, and G. Huey, "Use and views on social networking sites of pharmacy students in the United kingdom,"
American Journal of Pharmaceutical Education, vol. 77, no. 1, article 9, 2013.

[17] N. M. Foley, B. M. Maher, and M. A. Corrigan, "Social media and tomorrow's medical students-how do they fit?" Journal of Surgical Education, vol. 71, no. 3, pp. 385-390, 2014.

[18] D. M. Darda, "Observations by a university anatomy teacher and a suggestion for curricular change: integrative anatomy for undergraduates," Anatomical Sciences Education, vol. 3, no. 2, pp. 73-76, 2010.

[19] R. L. Drake, J. M. McBride, N. Lachman, and W. Pawlina, "Medical education in the anatomical sciences: the winds of change continue to blow," Anatomical Sciences Education, vol. 2, no. 6, pp. 253-259, 2009.

[20] N. A. Granger, D. C. Calleson, O. W. Henson et al., "Use of webbased materials to enhance anatomy instruction in the health sciences," The Anatomical Record Part B: The New Anatomist, vol. 289, no. 4, pp. 121-127, 2006.

[21] L. I. Rizzolo and W. B. Stewart, "Should we continue teaching anatomy by dissection when ...?" Anatomical Record B: New Anatomist, vol. 289, no. 6, pp. 215-218, 2006.

[22] P. J. O’Byrne, A. Patry, and J. A. Carnegie, “The development of interactive online learning tools for the study of anatomy," Medical Teacher, vol. 30, no. 8, pp. e260-e271, 2008.

[23] K. Ahmed, S. Rowland, V. Patel et al., "Is the structure of anatomy curriculum adequate for safe medical practice?" Surgeon, vol. 8, no. 6, pp. 318-324, 2010.

[24] K. J. A. H. Prince, A. J. A. A. Scherpbier, H. van Mameren, J. Drukker, and C. P. M. van der Vleuten, "Do students have sufficient knowledge of clinical anatomy?" Medical Education, vol. 39, no. 3, pp. 326-332, 2005.

[25] Y. Gupta, M. Morgan, A. Singh, and H. Ellis, "Junior doctors' knowledge of applied clinical anatomy," Clinical Anatomy, vol. 21, no. 4, pp. 334-338, 2008.

[26] C. H. Bagley, E. Gillott, and A. Gunasekera, "Undergraduate anatomy teaching: are we failing a generation of future surgeons?" The Bulletin of the Royal College of Surgeons of England, vol. 93, no. 1, pp. S26-S28, 2011.

[27] E. R. Hall, R. C. Davis, R. Weller, S. Powney, and S. B. Williams, "Doing dissections differently: a structured, peerassisted learning approach to maximizing learning in dissections," Anatomical Sciences Education, vol. 6, no. 1, pp. 56-66, 2013.

[28] S. K. Ghosh, "Evolution of illustrations in anatomy: a study from the classical period in Europe to modern times," Anatomical Sciences Education, vol. 8, no. 2, pp. 175-188, 2015.

[29] F. M. Corl, M. R. Garland, and E. K. Fishman, "Role of computer technology in medical illustration," American Journal of Roentgenology, vol. 175, no. 6, pp. 1519-1524, 2000.

[30] R. B. Trelease, "Anatomical informatics: millennial perspectives on a newer frontier," Anatomical Record, vol. 269, no. 5, pp. 224235, 2002.

[31] R. B. Trelease and A. Rosset, "Transforming clinical imaging data for virtual reality learning objects," Anatomical Sciences Education, vol. 1, no. 2, pp. 50-55, 2008.

[32] S. M. Attardi and K. A. Rogers, "Design and implementation of an online systemic human anatomy course with laboratory," Anatomical Sciences Education, vol. 8, no. 1, pp. 53-62, 2015.

[33] S. E. Van Nuland and K. A. Rogers, "The anatomy of E-learning tools: does software usability influence learning outcomes?" Anatomical Sciences Education, 2015. 
[34] M. M. Bakr, W. L. Massey, and H. Alexander, "Evaluation of Simodont ${ }^{\circledR}$ haptic 3D virtual reality dental training simulator," International Journal of Dental Clinics, vol. 5, no. 4, pp. 1-6, 2013.

[35] M. M. Bakr, W. L. Massey, and H. Alexander, "Students' evaluation of a 3DVR haptic device (Simodont ${ }^{5}$ ). Does early exposure to haptic feedback during preclinical dental education enhance the development of psychomotor skills?" International Journal of Dental Clinics, vol. 6, no. 2, pp. 1-7, 2014.

[36] A. Stirling and J. Birt, "An enriched multimedia eBook application to facilitate learning of anatomy," Anatomical Sciences Education, vol. 7, no. 1, pp. 19-27, 2014.

[37] I. P. Johnson, E. Palmer, J. Burton, and M. Brockhouse, "Online learning resources in anatomy: what do students think?" Clinical Anatomy, vol. 26, no. 5, pp. 556-563, 2013.

[38] M. Shachar and Y. Neumann, "Twenty years of research on the academic performance differences between traditional and distance learning: summative meta-analysis and trend examination," MERLOT Journal of Online Learning and Teaching, vol. 6, no. 2, pp. 318-334, 2010.

[39] I. Rolfe and J. McPherson, "Formative assessment: how am I doing?" The Lancet, vol. 345, no. 8953, pp. 837-839, 1995.

[40] P. Black and D. Wiliam, "Assessment and classroom learning," Assessment in Education, vol. 5, no. 1, pp. 7-74, 1998.

[41] S. B. Bierer, E. F. Dannefer, C. Taylor, P. Hall, and A. L. Hull, "Methods to assess students' acquisition, application and integration of basic science knowledge in an innovative competency-based curriculum," Medical Teacher, vol. 30, no. 7, pp. e171-e177, 2008.

[42] M. T. Carrillo-de-la-Peña, E. Baillès, X. Caseras, À. Martínez, G. Ortet, and J. Pérez, "Formative assessment and academic achievement in pre-graduate students of health sciences," Advances in Health Sciences Education: Theory and Practice, vol. 14, no. 1, pp. 61-67, 2009.

[43] D. J. R. Evans, P. Zeun, and R. A. Stanier, "Motivating student learning using a formative assessment journey," Journal of Anatomy, vol. 224, no. 3, pp. 296-303, 2014.

[44] A. L. O. Webb and S. Choi, "Interactive radiological anatomy eLearning solution for first year medical students: development, integration, and impact on learning," Anatomical Sciences Education, vol. 7, no. 5, pp. 350-360, 2014.

[45] E. G. Beale, P. M. Tarwater, and V. H. Lee, "A retrospective look at replacing face-to-face embryology instruction with online lectures in a human anatomy course," Anatomical Sciences Education, vol. 7, no. 3, pp. 234-241, 2014.

[46] J. A. Carnegie, "The use of limericks to engage student interest and promote active learning in an undergraduate course in functional anatomy," Anatomical Sciences Education, vol. 5, no. 2, pp. 90-97, 2012.

[47] D. S. Shin, D. H. Kim, J. S. Park, H. G. Jang, and M. S. Chung, "Evaluation of anatomy comic strips for further production and applications," Anatomy and Cell Biology, vol. 46, no. 3, pp. 210216, 2013.

[48] W. C. McGaghie, S. B. Issenberg, E. R. Petrusa, and R. J. Scalese, "Effect of practice on standardised learning outcomes in simulation-based medical education," Medical Education, vol. 40, no. 8, pp. 792-797, 2006.

[49] A. J. Azzi, C. J. Ramnanan, J. Smith, É. Dionne, and A. Jalali, "To quiz or not to quiz: formative tests help detect students at risk of failing the clinical anatomy course," Anatomical Sciences Education, vol. 8, no. 5, pp. 413-420, 2015.
[50] I. M. Inuwa, V. Taranikanti, M. Al-Rawahy, and O. Habbal, "Anatomy practical examinations: how does student performance on computerized evaluation compare with the traditional format?" Anatomical Sciences Education, vol. 5, no. 1, pp. 27-32, 2012.

[51] M. Prensky, Digital Game-Based Learning, McGraw-Hill, New York, NY, USA, 2nd edition, 2004.

[52] W. B. Kennedy, P. R. Kelley, and M. Saffran, "Use of NBME examinations to assess retention of basic science knowledge," Journal of Medical Education, vol. 56, no. 3, pp. 167-173, 1981.

[53] G. Norman, "The essential role of basic science in medical education: the perspective from psychology," Clinical and Investigative Medicine, vol. 23, no. 1, pp. 47-51, 2000.

[54] Y. Ling, D. B. Swanson, K. Holtzman, and S. D. Bucak, "Retention of basic science information by senior medical students," Academic Medicine, vol. 83, no. 10, supplement, pp. S82-S85, 2008.

[55] E. J. F. M. Custers and O. T. J. ten Cate, "Very long-term retention of basic science knowledge in doctors after graduation," Medical Education, vol. 45, no. 4, pp. 422-430, 2011.

[56] M. D. Lazarus, V. M. Chinchilli, S. L. Leong, and G. L. Kauffman Jr., "Perceptions of anatomy: critical components in the clinical setting," Anatomical Sciences Education, vol. 5, no. 4, pp. 187199, 2012.

[57] H. Jenkins, "From youtube to you niversity," The Chronicle of Higher Education, vol. 53, no. 24, pp. B9-B10, 2007.

[58] A. A. Jaffar, "YouTube: an emerging tool in anatomy education," Anatomical Sciences Education, vol. 5, no. 3, pp. 158-164, 2012.

[59] A. A. Jaffar, "Exploring the use of a facebook page in anatomy education," Anatomical Sciences Education, vol. 7, no. 3, pp. 199208, 2014.

[60] H. Schmidt, "Integrating the teaching of basic sciences, clinical sciences, and biopsychosocial issues," Academic Medicine, vol. 73, no. 9, pp. S24-S31, 1998.

[61] J. H. Muller, S. Jain, H. Loeser, and D. M. Irby, "Lessons learned about integrating a medical school curriculum: perceptions of students, faculty and curriculum leaders," Medical Education, vol. 42, no. 8, pp. 778-785, 2008.

[62] M. Cook, D. M. Irby, and B. C. O’Brien, Educating Physicians: A Call for Reform of Medical School and Residency, JosseyBass, San Franscisco, Calif, USA, 1st edition, 2010.

[63] M. M. Cuddy, D. B. Swanson, R. L. Drake, and W. Pawlina, "Changes in anatomy instruction and USMLE performance: empirical evidence on the absence of a relationship," Anatomical Sciences Education, vol. 6, no. 1, pp. 3-10, 2013.

[64] R. A. Green and D. L. Hughes, "Student outcomes associated with use of asynchronous online discussion forums in gross anatomy teaching," Anatomical Sciences Education, vol. 6, no. 2, pp. 101-106, 2013.

[65] O. P. Gobée, D. Jansma, and M. C. Deruiter, "AnatomicalTerms.info: heading for an online solution to the anatomical synonym problem hurdles in data-reuse from the Terminologia Anatomica and the foundational model of anatomy and potentials for future development," Clinical Anatomy, vol. 24, no. 7, pp. 817-830, 2011. 


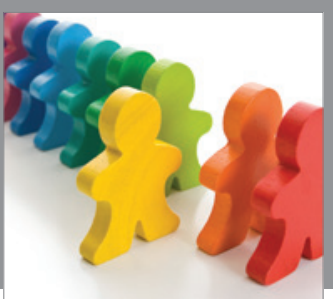

Autism

Research and Treatment
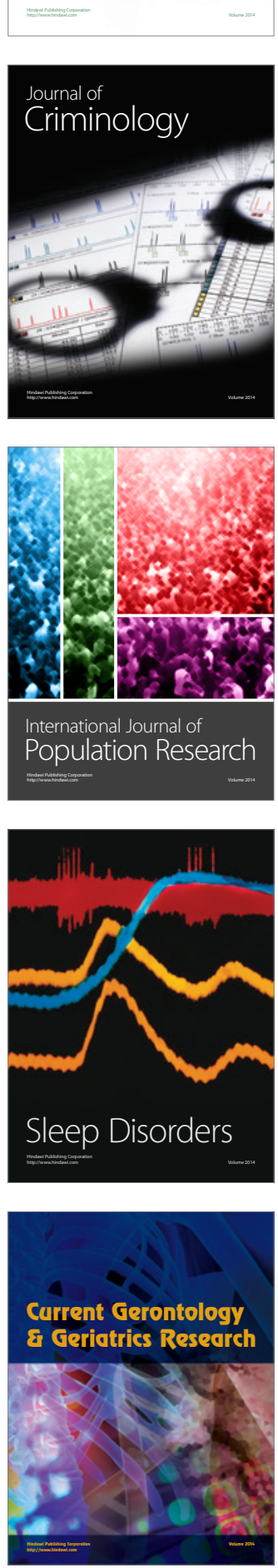

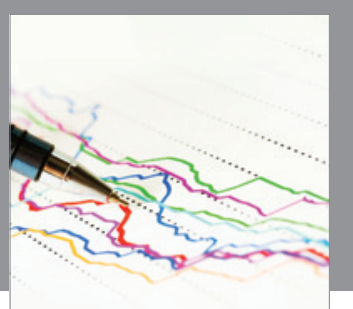

Economics

Research International
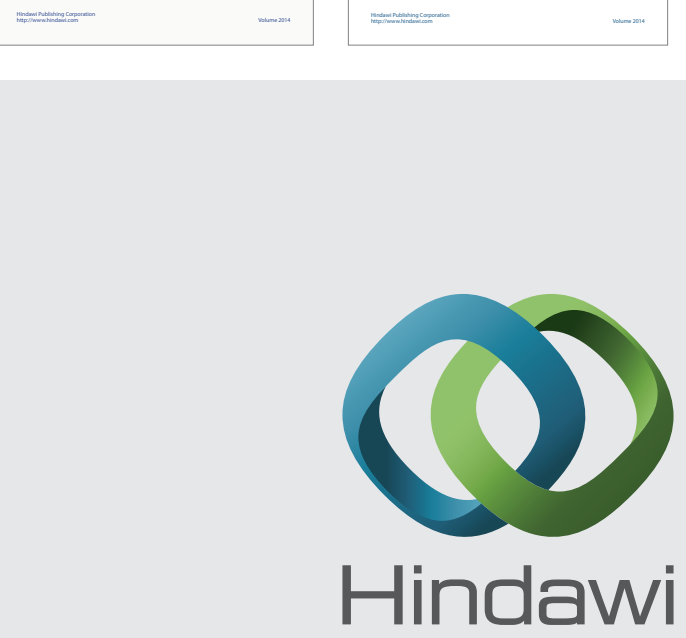

Submit your manuscripts at

http://www.hindawi.com
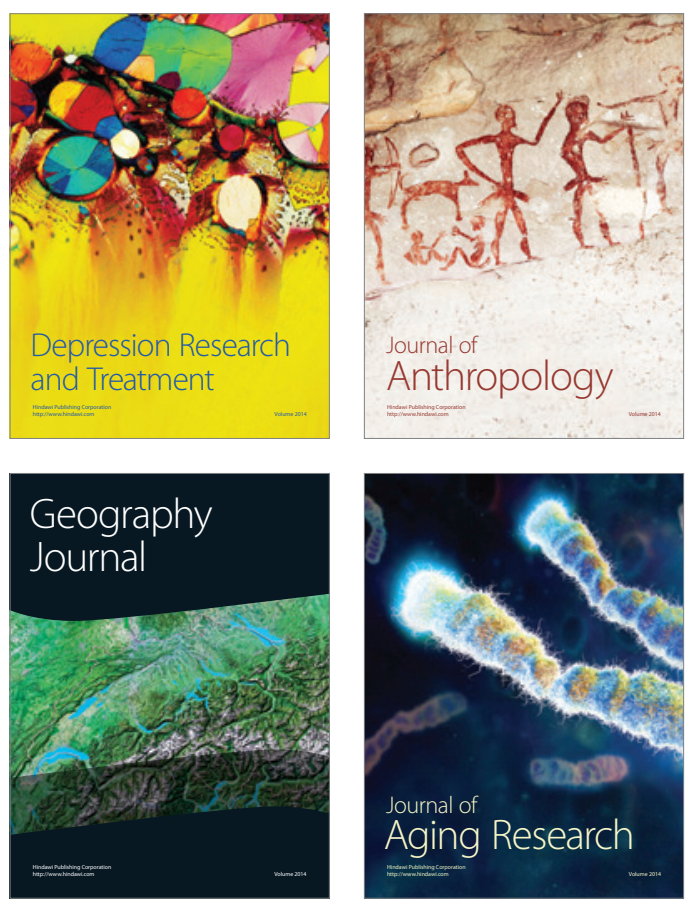
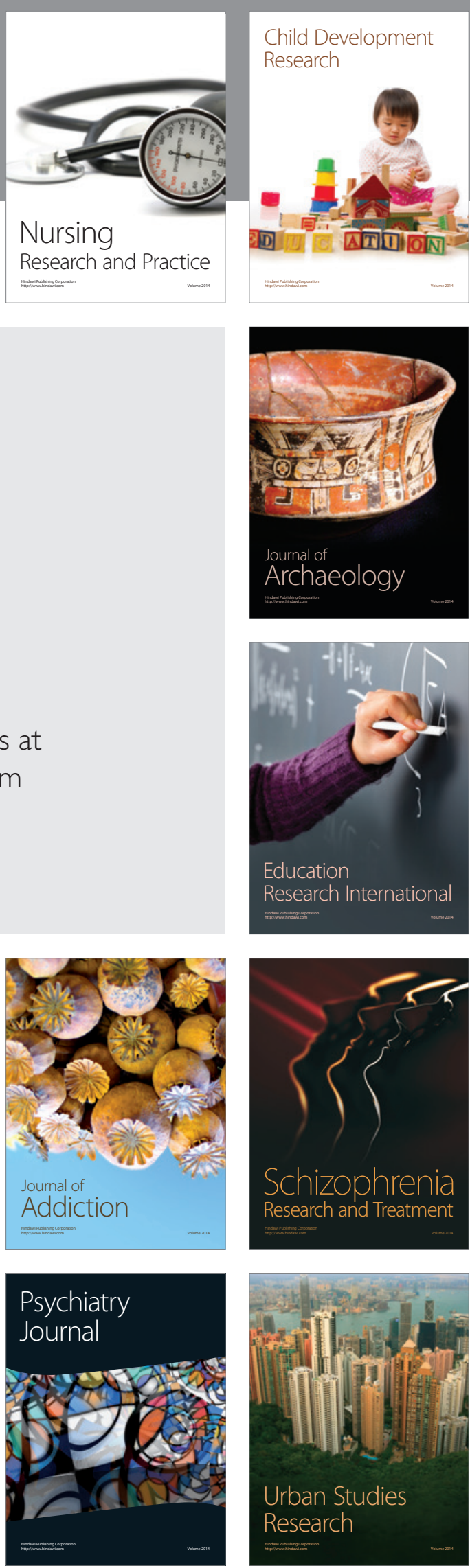